\title{
Multivariate life-history indices of exploited coral reef fish populations used to measure the performance of no-take zones in a marine protected area
}

\author{
Gavin A. Begg, Bruce D. Mapstone, Ashley J. Williams, Samantha Adams, \\ Campbell R. Davies, and Dong C. Lou
}

\begin{abstract}
We investigate the use of multivariate life-history indices to assess the performance of no-take zones with respect to ameliorating the impacts of harvest on exploited coral reef fish populations in the Great Barrier Reef Marine Park. A range of life-history parameters were estimated for the two major target species of the Great Barrier Reef (GBR) line fishery, common coral trout (Plectropomus leopardus) and red throat emperor (Lethrinus miniatus), collected from five adjacent reefs (three of which were closed to all forms of fishing) in each of three geographically dispersed regions between 1995 and 1998. Life-history parameters were used to compare the status of populations on open and closed reefs over regions and years. Principal components (PC) analyses were used to effectively reduce the number of parameters to four significant PCs for each species, accounting for $84 \%$ and $94 \%$ of the total variation in the data for common coral trout and red throat emperor, respectively. We were able to clearly identify those populations that were sampled from reefs open or closed to fishing based on the multivariate descriptors of life-history parameters. The concurrent use of several life-history indices maximised our potential to differentiate changes related to no-take zones from background variation.
\end{abstract}

Résumé : Nous examinons l'utilisation des indices démographiques multidimensionnels pour évaluer la performance des zones de protection marines (MPA) établies pour atténuer l'impact de la récolte sur les populations de poissons des récifs coralliens dans le parc marin de la Grande Barrière de Corail. Nous avons estimé un nombre de variables démographiques pour les deux espèces qui sont le plus couramment ciblées par la pêche à la ligne sur la Grande Barrière de Corail (GBR), la loche saumonée (Plectropomus leopardus) et l'empereur gueule longue (Lethrinus miniatus), récoltées sur cinq récifs adjacents (dont trois où toute forme de pêche est interdite) dans chacune de trois régions séparées géographiquement de 1995 à 1998. Les variables démographiques ont servi à comparer l'état des populations dans les récifs protégés et non protégés au cours des années dans les différentes régions. Des analyses des composantes principales $(\mathrm{PC})$ ont permis de réduire le nombre de variables à quatre $\mathrm{PC}$ significatives pour chaque espèce, expliquant ainsi respectivement $84 \%$ et $94 \%$ de la variation totale des données pour la loche saumonée et l'empereur gueule longue. Les descripteurs multidimensionnels des variables démographiques nous ont permis de distinguer clairement les populations échantillonnées sur les récifs protégés et sur les récifs non protégés. L'utilisation conjointe de plusieurs indices démographiques a maximisé notre capacité de reconnaitre les changements dus à la présence des MPA de la variation sous-jacente.

[Traduit par la Rédaction]

\section{Introduction}

Increasing impacts on natural resources of marine ecosystems, coupled with ineffective fisheries management and the need to maintain biodiversity in perpetuity, have led to implementations of marine protected areas (MPAs) around the globe. One management strategy frequently promoted within MPAs is the concept of "no-take" zones where all extractive activities such as fishing and collecting are prohibited. Although the concept of no-take zones has been around for decades (Beverton and Holt 1957), their use as an alternate ecosystem-based management strategy is relatively new

Received 10 November 2003. Accepted 4 December 2004. Published on the NRC Research Press Web site at http://cjfas.nrc.ca on 14 April 2005.

$\mathrm{J} 17830$

G.A. Begg, ${ }^{1}$ B.D. Mapstone, ${ }^{2}$ A.J. Williams, S. Adams, C.R. Davies, ${ }^{3}$ and D.C. Lou. ${ }^{4}$ CRC Reef Research Centre, School of Tropical Environment Studies and Geography, James Cook University, Townsville, 4811 Queensland, Australia.

${ }^{1}$ Corresponding author (e-mail: gavin.begg@jcu.edu.au).

${ }^{2}$ Present address: Antarctic Climate and Ecosystems CRC, Private Bag 80, Hobart, 7001 Tasmania, Australia.

${ }^{3}$ Present address: CSIRO Marine Research, GPO Box 1538, Hobart, 7001 Tasmania, Australia.

${ }^{4}$ Present address: School of Marine Biology and Aquaculture, James Cook University, Townsville, 4811 Queensland, Australia. 
(Roberts and Polunin 1991; Agardy 1997; Russ 2002). In this study, we examine the utility of multivariate life-history indices, generated from a suite of life-history parameters of exploited coral reef fish populations, to assess the degree to which no-take zones ameliorated the impacts of fishing within the Great Barrier Reef Marine Park (GBRMP) and World Heritage Area (GBRWHA), Australia. No-take zones are a vital part of the multiple-use zoning approach applied in the GBRMP (Day 2002) and have recently been increased to comprise $33 \%$ of the entire Marine Park (GBRMPA 2004).

MPAs have increased in popularity as an alternate management strategy because of the poor state of global fisheries resources and the failure of traditional fisheries management to stem the flow of overcapitalised and overexploited fisheries (Roberts and Polunin 1991; Fogarty et al. 2000; Russ 2002). Traditional fisheries management typically has been based on single-species and stock-specific strategies that have failed to encompass the diversity of multispecies and metastock assemblages, leading to the depletion, extirpation, and collapse of fish stocks throughout the world. Management problems are exacerbated in coral reef fisheries, which tend to be data-limited, community-based, and inherently complex as the result of multispecies and multigear interactions (Crowder et al. 2000). MPAs, however, potentially provide an expedient and efficient ecosystem-based management strategy that embodies the directives of the precautionary approach, fulfilling the dual functionality of biodiversity conservation and, potentially, sustainable utilisation of selected resources (Agardy 1997; Bohnsack 2000).

Several authors have argued that no-take zones can provide an array of potential benefits to fisheries, both ecological and socio-economic, in the face of management uncertainty (e.g., Roberts and Polunin 1991; Murray et al. 1999; Fogarty et al. 2000). Postulated benefits of no-take zones include the following: provision of sanctuary for exploited species from anthropogenic impacts; maintenance of species, population, and habitat biodiversity; protection of ecosystem structure and function; and insurance against fisheries recruitment and management failure (Roberts and Polunin 1991; Bohnsack 1998; Agardy 2000). Recent studies have indicated that abundance, biomass, and (or) size of target species increase within the boundaries of no-take zones (e.g., Buxton 1993; Dugan and Davis 1993; Halpern and Warner 2002), potentially leading to spill-over and larval dispersal effects that might increase fishery yields and replenish unproductive or "sink" habitats in adjacent unprotected areas (Russ and Alcala 1996a; Roberts et al. 2001; Halpern 2003). Moreover, no-take zones are considered to be particularly effective in the preservation of coral reef fish species, which tend to be relatively sedentary as adults but widely dispersed as larvae, thereby providing a mechanism for the protection of refuges of spawning stock biomass from which harvested local populations elsewhere might be replenished (Bohnsack 2000).

Despite the widespread advocacy of MPAs and no-take zones, however, their performance has proved difficult to measure because most are established without any clearly defined objectives against which their success (or otherwise) can be evaluated (Agardy 2000). Reviews of MPAs, includ- ing no-take zones, and modelling studies evaluating their hypothetical performance abound in the scientific literature (e.g., Polacheck 1990; Allison et al. 1998; Russ 2002), but fewer well-designed and replicated empirical studies testing specific hypotheses exist (but see, for example, Buxton 1993; Russ and Alcala 1996b; Mapstone et al. 2004). Typically, once a MPA or a no-take zone is established, there is little follow-up to assess the performance or efficacy of the area, even though routine monitoring and assessment studies should be the default scenario to facilitate performance assessment and review. Those studies that do exist tend to be limited on a spatial and (or) temporal scale (Russ and Alcala 1996b; Mapstone et al. 1999), restricting the generalities that can be derived from such studies (Russ 2002; Adams 2002; Mapstone et al. 2004); however, meta-analysis approaches may provide some insight (Mosquera et al. 2000). Furthermore, performances of the respective no-take zones are often limited to gross measures of abundance, biomass, or size of individuals (see reviews of Russ 2002 and Halpern 2003).

Multiple-use MPAs have been established to protect and conserve complex coral reef ecosystems such as those in the GBRMP where precautionary principles of conservation are rated very highly. The Great Barrier Reef (GBR) is the largest coral reef ecosystem in the world, and the GBRMP was established in 1975 to facilitate conservation management of most of the GBR. In 1981, an area including the GBRMP was inscribed on the World Heritage list as the GBRWHA. The GBRMP contains a number of no-take zones, the best known and most widespread are the Marine National Park Zones (locally referred to as "green" zones). Until recently, no-take zones accounted for about $5 \%$ of the total area of the GBRMP and approximately $24 \%$ of the area of the mapped coral reef habitat in the Marine Park. A major rezoning program, called the Representative Areas Program, was undertaken by the Great Barrier Reef Marine Park Authority (GBRMPA) and resulted in a more comprehensive, adequate, and representative zoning network encompassing all habitats and increased the coverage of no-take zones to $33 \%$ of the entire GBRMP. The legislation for the GBRMP sets out the broad objectives of zoning, requiring both conservation and protection of biodiversity while allowing multiple uses, including fishing in some zones.

Fishing is the major extractive use on the GBR, with the various zones determining what activities can occur. The reef line fishery is one of a variety of commercial fisheries, with an annual economic value of about AU\$60-100 million. Each year the commercial sector harvests between 3000 and 4000 tonnes (t) from the multispecies reef line fishery of the GBR, while significant quantities are also harvested by the recreational $(\sim 2000 \mathrm{t})$ and charter boat $(\sim 300 \mathrm{t})$ sectors. Common coral trout (Plectropomus leopardus) and red throat emperor (Lethrinus miniatus) are the two major target species of the reef line fishery for all sectors in most regions of the GBRWHA, comprising nearly $50 \%$ of the total catch (Higgs 1996; Mapstone et al. 1996, 2004). In addition to the use of no-take zones, current management strategies for the reef line fishery include seasonal spawning closures and size limits for all sectors, limited entry and an individual transferable catch quota system for the commer- 
Table 1. Total number of common coral trout (Plectropomus leopardus) and red throat emperor (Lethrinus miniatus) sampled during the Effects of Line Fishing (ELF) Experiment, 1995-1998.

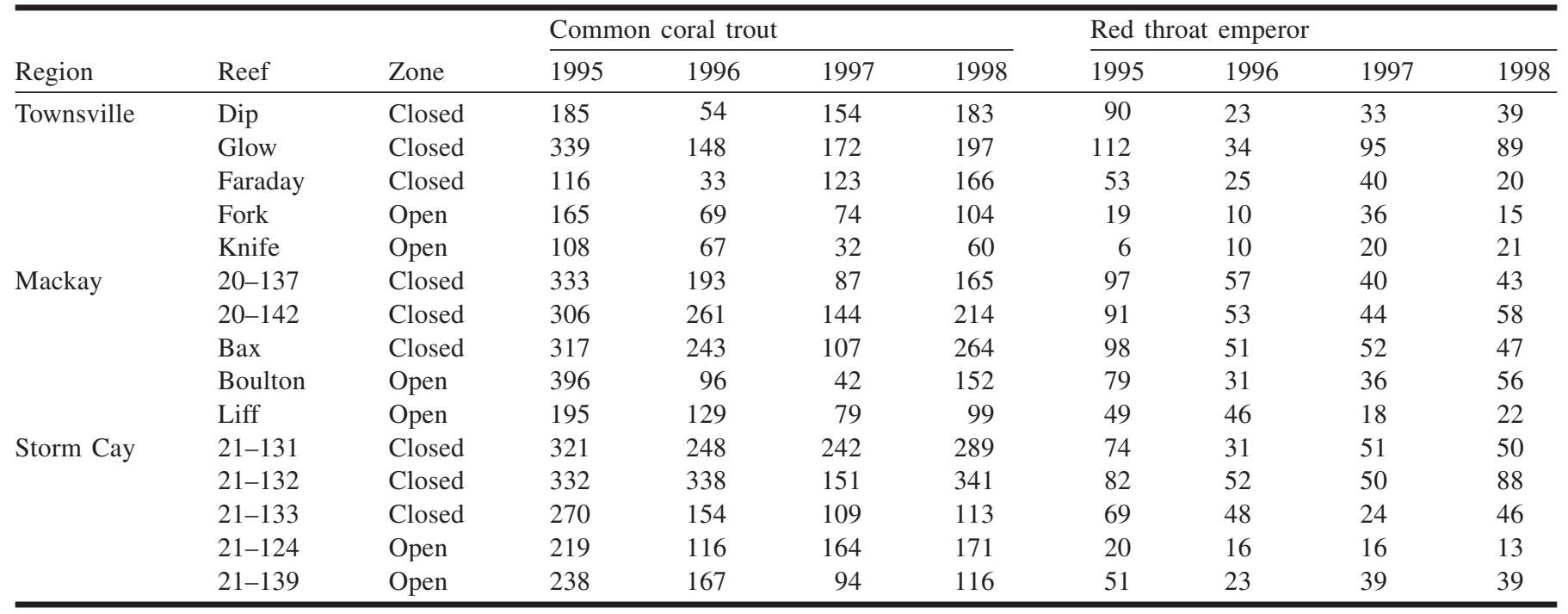

cial sector, and hook and bag limits for the recreational sector.

Protection from significant fishing mortality via the establishment of no-take zones would be predicted to precipitate, over time, several contrasts between the closed areas and those that remained open to exploitation. Fish in the no-take zones would be expected on average to be more abundant and larger, have increased survivorship, and possibly different population level reproductive characteristics than those in the open areas. Both species considered in this study have been shown to be protogynous hermaphrodites (Ferreira 1995; Adams 2003; Bean et al. 2003), and common coral trout has been shown to be diandric (Adams 2003). Consequently, despite the presence of some small, young males, the larger, older groups of these species are generally maledominated (Adams et al. 2000; Bean et al. 2003). Fishing has a tendency to disproportionately reduce the abundance of these larger, older males through either direct removal or increased mortality of younger fish (Vincent and Sadovy 1998), potentially leading to larger females changing sex earlier and so also reducing the average age and size of females in the population (Adams 2002). If sex change is insufficiently flexible, however, or fishing removes males at a rate faster than can be replaced by earlier sex change, a highly female-biased sex ratio is expected (Vincent and Sadovy 1998; Adams 2002). In the latter case, it would be expected that sex ratios on reefs open to fishing would be significantly more female-biased than those on reefs closed to fishing.

We assess the relative effects of no-take zones on lifehistory parameters of the two major target reef fish species over large spatial and temporal scales on the GBR based on a suite of multivariate indices. This multivariate approach reduces the dimensionality in the data while assimilating the influence of a range of individual life-history parameters. We discuss the utility of these indices in evaluating the performance of no-take zones and propose strategies for applying them to monitor the relative success of no-take zones for their potential contribution to the conservation and sustainability of exploited coral reef fish populations.

\section{Materials and methods}

\section{Sample collection}

Common coral trout and red throat emperor samples were collected between 1995 and 1998 from research line fishing catch surveys for the Effects of Line Fishing (ELF) Experiment (Davies et al. 1998; Mapstone et al. 2004) implemented by the Cooperative Research Centre for the Great Barrier Reef World Heritage Area (CRC Reef). Samples were collected from clusters of six adjacent reefs in four geographic regions. Four of the six reefs in each region had been no-take zones and closed to all forms of fishing for 10-12 years before 1995. The remaining two reefs in each cluster were historically open to fishing and provided the necessary "impact" treatment against which the performance of the no-take zones could be assessed. For the purposes of this study, we analysed multivariate life-history indices derived from a range of life-history parameters for common coral trout and red throat emperor from three of the closed reefs and the two open reefs in three of the four regions (Townsville, Mackay, and Storm Cay) (Table 1; Fig. 1). Typically, red throat emperor does not occur in the fourth region (around Lizard Island, $14^{\circ} \mathrm{S}$ ) and so data from that region were not considered for this study. The fourth closed reef in each region was excluded because it was subjected to experimental fishing in 1997 as part of the CRC Reef ELF Experiment, effectively losing its MPA status, and therefore was not comparable to either the three closed reefs or the two open reefs.

All reefs were sampled each year in the austral spring (October-December) to coincide with the peak spawning period of the main target species, common coral trout. Each reef was divided into six approximately equal-sized, contiguous blocks and sampled on a single day on each sampling occasion. Standardised commercial reef line fishing effort 
Fig. 1. Location of the Effects of Line Fishing (ELF) Experimental clusters of reefs (Townsville, Mackay, Storm Cay) from which samples of common coral trout (Plectropomus leopardus) and red throat emperor (Lethrinus miniatus) were analysed for this study. Asterisks (*) indicate reefs closed to fishing (no-take zone).

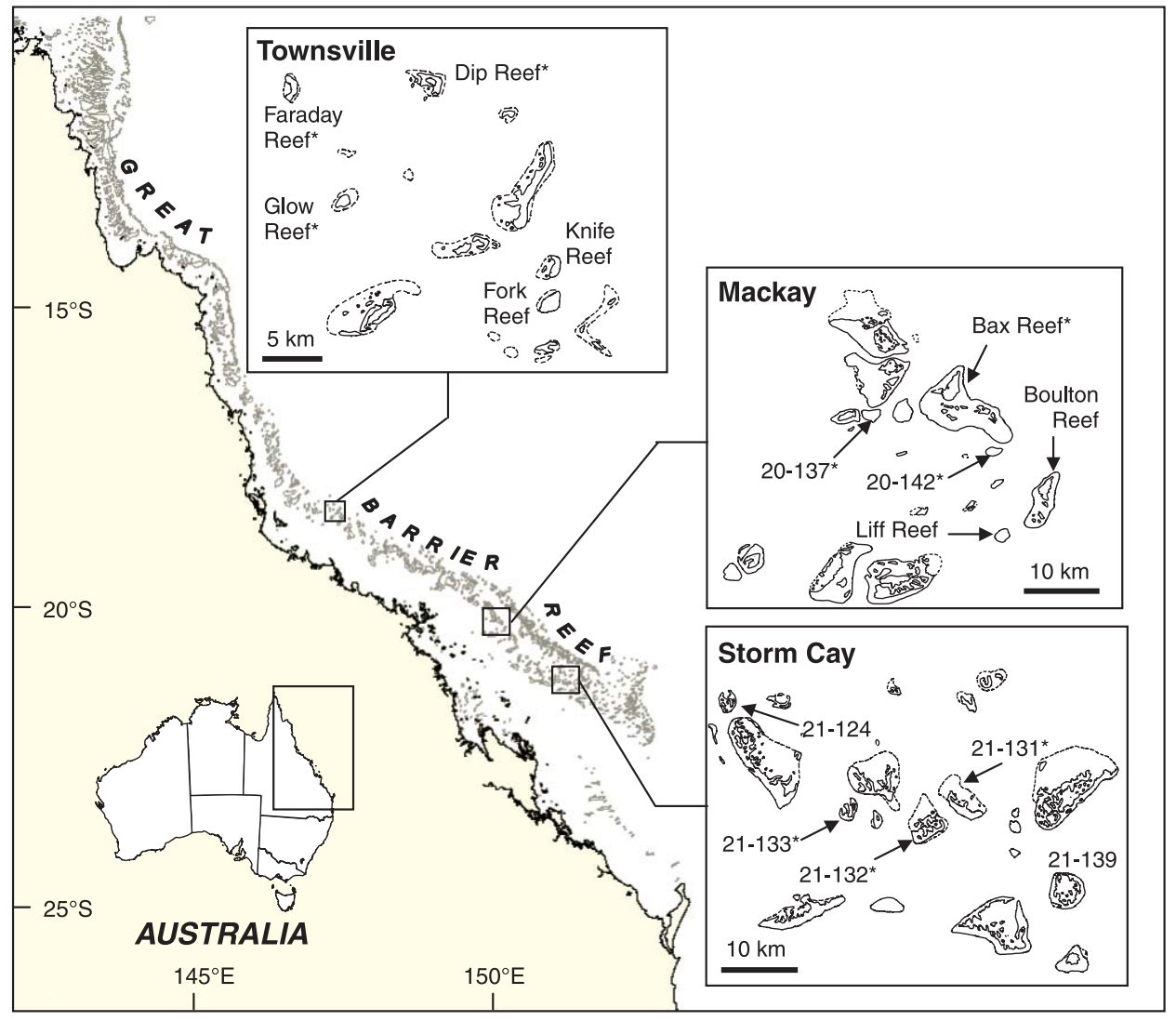

was distributed uniformly across two depth strata within each block. Consequently, diel variations in catch rates, if present, did not affect the outcomes of the study because of the standardised method of sampling where any differences would be relative and applicable across all reefs. All fish caught were measured, tagged for later identification, and kept for weighing and extraction of gonads and otoliths. For further sampling details of the ELF Experiment, see Davies et al. (1998) and Mapstone et al. (2004).

Samples of common coral trout and red throat emperor were aged using standardised methods developed by Ferreira and Russ (1994) and Williams et al. (2003), respectively. In addition, gonads from a random subsample of common coral trout were extracted for histological examination and form the basis of the reproductive parameters used in this study. Common coral trout were classified into functional reproductive categories following Adams et al. (2000).

\section{Parameter estimation}

A suite of life-history parameters was estimated from the samples collected for each species at each reef to test the relative performance of no-take zones in the GBRMP (Table 2). Age (Age) and length (Len) richness were used as proxies for age and size frequency distributions, respectively, and estimated for the harvested portion of the population as the number of age (years) and length $(10 \mathrm{~mm})$ groups above the minimum legal sizes for the fishery. Harvested populations of common coral trout and red throat emperor were
Table 2. Description of life-history parameters used in the analyses.

\begin{tabular}{ll}
\hline Life-history parameter & Description \\
\hline Age & Number of age groups (years) \\
Len & Number of length groups $(10 \mathrm{~mm})$ \\
LAA & Mean length-at-age \\
WAA & Mean weight-at-age \\
$A_{90}$ & 90th percentile of age \\
$L_{90}$ & 90th percentile of length \\
$W_{90}$ & 90th percentile of weight \\
$S$ & Survivorship estimated from instanta- \\
& neous mortality rate (e ${ }^{-Z}$ ) \\
$A_{\text {fem }}$ & 90th percentile of age of mature females \\
$L_{\text {fem }}$ & 90th percentile of length of mature \\
Sex & females \\
& Operational sex ratio based on propor- \\
Abun & tion of mature males to females \\
Biom & Relative CPUE index of abundance \\
\hline
\end{tabular}

Note: Harvested population of common coral trout (Plectropomus leopardus) and red throat emperor (Lethrinus miniatus) were fish equal to or greater than $358-\mathrm{mm}$ and $322-\mathrm{mm}$ fork length (FL), respectively. These FLs correspond to the minimum legal total lengths for harvest of $380 \mathrm{~mm}$ and $350 \mathrm{~mm}$, respectively. Mean length- and weight-at-age were estimated for common coral trout fully recruited to the fishery at age 4 years. CPUE, catch-per-unit-effort. 
considered to be fish equal to or greater than the minimum legal sizes of 358- and 322-mm fork length (FL), respectively. Similarly, the 90th percentiles of age $\left(A_{90}\right)$, fork length $\left(L_{90}\right)$, and weight $\left(W_{90}\right)$ were estimated for the harvested portion of the respective populations and used as relative indices of senescence, longevity, and growth potential. Catch-per-unit-effort (CPUE) of the total number of fish caught $\cdot \mathrm{min}^{-1}$ (Abun) and total weight of fish caught $\cdot \mathrm{min}^{-1}$ (Biom) were also estimated for the harvested portions of the populations of each species and used as relative indices of abundance and biomass, respectively.

Additional life-history parameters (LAA, WAA, $S, A_{\mathrm{fem}}$, $L_{\text {fem }}$, Sex) (Table 2) were estimated for common coral trout because of their numerical abundance in the catch and importance as the major target species in the reef line fishery. Common coral trout were considered to be fully recruited to the fishery at 4 years of age, the age at which mean lengthat-age (LAA) and weight-at-age (WAA) were estimated. Instantaneous rates of total mortality $(Z)$ were estimated from age-based catch curves for fully recruited fish and used to calculate survivorship $\left(S=\mathrm{e}^{-Z}\right.$ ) (Beverton and Holt 1957). Age-based catch curves assume constant recruitment among the fully recruited age groups over time (Quinn and Deriso 1999). Although this assumption was untested for common coral trout, there was no clear evidence of significant recruitment events in the observed age frequency distributions. Catch curve regressions were fitted from the first fully selected age group (4 years) through to the oldest age group that was preceded by no more than two consecutive zero frequencies. As a result, the age range used to estimate $S$ varied slightly among reefs. There were insufficient data to estimate $S$ for one of the closed reefs in the Townsville region in 1996 and 1998 and for one of the open reefs off Townsville in 1997. Consequently, estimates of $S$ for each of these reefs in the years with poor data were imputed as the mean value for that reef from the remaining years.

The 90th percentiles of age $\left(A_{\mathrm{fem}}\right)$ and fork length $\left(L_{\mathrm{fem}}\right)$ of mature females and the operational sex ratio (Sex) of mature males to mature females were also estimated for $P$. leopardus sampled at each reef (Table 2). There were insufficient data to estimate the sex ratio for one of the open reefs in the Townsville region in 1997 and so an estimate was imputed as the mean value across the remaining years for that reef.

\section{Statistical analysis}

Multivariate statistical analyses were used to examine the effects of year (1995-1998), region (Townsville, Mackay, Storm Cay), and reef zone (open, closed) on a suite of life-history parameters for each species. The numerous lifehistory parameters were used to construct multivariate life-history indices for the two species at each reef to test for discrimination between the closed (no-take) and open reefs. Principal components analysis (PCA) was used initially to reduce the dimensionality in the multivariate data. The original data were transformed to values standardised against their means by their standard deviation because of the different measurement scales of the various parameters and then transformed into principal components (PCs). Consequently, the PCs were weighted averages of the normalised estimates of life-history parameters and as such can be interpreted as multivariate life-history indices. Individual PCs that accounted for $5 \%$ or more of the total variation in the data were selected for further analysis. The PC loadings were used to provide a summary of the influence of the original parameters, and biplots were used to represent both the original parameters and transformed observations on pairs of PCs.

Repeated-measures analysis of variance was then used to test the within-group (repeated-measures) effect of year and the between-group effects of region and zone and their interactions for common coral trout and red throat emperor on each significant PC selected in the data-reduction step (SAS 1989). Sphericity tests were used to examine the assumption of type-H covariance structure for the within-group effects, and the Huynh-Feldt estimator was used to adjust tests of significance if this assumption was not satisfied (SAS 1989). Significance criteria were also adjusted for multiple testing of the individual PC multivariate life-history indices using the Bonferroni adjustment (Sokal and Rohlf 1995). Jackknifed cross-validation procedures were used to estimate unbiased classification rates of open and closed reefs based on the significant PC scores.

\section{Results}

The initial PCAs for common coral trout and red throat emperor were based on all data, incorporating the effects of year (1995-1998), region (Townsville, Mackay, Storm Cay), and zone (open, closed) on the full suite of life-history parameters. From the 13 parameters (Age, Len, LAA, WAA, $A_{90}, L_{90}, W_{90}, S, A_{\text {fem }}, L_{\text {fem }}$, Sex, Abun, Biom) for common coral trout and seven parameters (Age, Len, $A_{90}, L_{90}, W_{90}$, Abun, Biom) for red throat emperor (Table 1), the PCAs identified four significant principal components (PCs) for each species (Table 3). Additional PCs could be discarded with relatively little loss of explanatory information. The four PCs combined explained $84 \%$ and $94 \%$ of the total variation in the data for common coral trout and red throat emperor, respectively (Table 3 ).

\section{Effects of zone}

Significant and unconfounded main effects of zone were evident on PC I for both common coral trout and red throat emperor (Table 4; Fig. 2), indicating an effect of zone across the aggregate weighted average scores of all parameters (Table 3). Populations of common coral trout sampled on reefs closed to fishing tended to have broader age and length distributions, older, larger and heavier individuals, greater abundance and biomass, higher survivorship, more males, and larger and older females, all indicators of a healthy population (Fig. 3). Like common coral trout, populations of red throat emperor sampled on reefs closed to fishing tended to have broader age and length distributions and greater abundance and biomass (Fig. 3). In contrast, there was no consistent pattern in the morphometric life-history parameters $\left(A_{90}\right.$, $L_{90}, W_{90}$ ) for red throat emperor sampled on reefs open and closed to fishing. The PC I loadings and relative magnitude of the influence of these parameters were typically lower than those observed for the other life-history parameters (Abun, Biom, Age, Len) (Table 3; Fig. 3). 
Table 3. Significant (equal or greater than 5\% of the total variation in the data) principal components (PCs) and PC loadings of life-history parameters for common coral trout (Plectropomus leopardus) and red throat emperor (Lethrinus miniatus) collected from open and closed reefs off Townsville, Mackay, and Storm Cay, 1995-1998.

\begin{tabular}{|c|c|c|c|c|}
\hline Life-history parameter & PC I & PC II & PC III & PC IV \\
\hline \multicolumn{5}{|l|}{ (a) Common coral trout } \\
\hline Age & 0.353 & 0.127 & & \\
\hline Len & 0.353 & 0.155 & 0.149 & -0.177 \\
\hline LAA & & -0.488 & 0.344 & 0.306 \\
\hline WAA & & -0.468 & 0.376 & 0.321 \\
\hline$A_{90}$ & 0.303 & & -0.447 & \\
\hline$L_{90}$ & 0.366 & -0.127 & & \\
\hline$W_{90}$ & 0.369 & -0.123 & & \\
\hline$S$ & 0.210 & -0.220 & -0.449 & 0.264 \\
\hline$A_{\mathrm{fem}}$ & 0.285 & -0.142 & -0.334 & \\
\hline$L_{\mathrm{fem}}$ & 0.242 & -0.264 & & -0.487 \\
\hline Sex & 0.119 & 0.381 & & 0.669 \\
\hline Abun & 0.289 & 0.327 & 0.315 & \\
\hline Biom & 0.309 & 0.282 & 0.303 & \\
\hline Proportion of variance & 0.45 & 0.20 & 0.13 & 0.06 \\
\hline Cumulative proportion & 0.45 & 0.65 & 0.78 & 0.84 \\
\hline \multicolumn{5}{|l|}{ (b) Red throat emperor } \\
\hline Age & 0.421 & & 0.629 & -0.104 \\
\hline Len & 0.365 & 0.326 & & -0.772 \\
\hline$A_{90}$ & & -0.482 & 0.581 & 0.180 \\
\hline$L_{90}$ & 0.244 & -0.558 & -0.237 & -0.184 \\
\hline$W_{90}$ & 0.227 & -0.528 & -0.396 & -0.198 \\
\hline Abun & 0.525 & 0.241 & -0.119 & 0.350 \\
\hline Biom & 0.547 & 0.104 & -0.192 & 0.406 \\
\hline Proportion of variance & 0.39 & 0.33 & 0.14 & 0.08 \\
\hline Cumulative proportion & 0.39 & 0.72 & 0.86 & 0.94 \\
\hline
\end{tabular}

Note: See Table 2 for explanation of abbreviations.

Zone effects were suggested also on PC III for common coral trout, but in interaction with year and region (Table 4). Bi-plots of the interaction on PC III indicated, however, that there were no consistent regional patterns for common coral trout sampled on open and closed reefs for each year (Fig. 4). In 1995, common coral trout on open and closed reefs off Townsville, Mackay, and Storm Cay appeared to be distinct, with no overlap in their PC III scores (Fig. 4). Similarly, in 1996 off Mackay and Storm Cay and in 1998 off Townsville and Mackay, there was no overlap in the PC III scores for common coral trout from open or closed reefs (Fig. 4). $S, A_{90}$, WAA, and LAA were the main parameters underlying the effect of PC III (Table 3). Zone effects were not clearly separated on either PC II or PC IV, either as main effects or in interaction with region or year for common coral trout or red throat emperor (Table 4).

\section{Effects of region}

Regional effects varied significantly with year on PC II for common coral trout and on PC I for red throat emperor (Fig. 5), varied with both year and zone on PC III for common coral trout (Fig. 4), and were evident as an unconfounded main effect for red throat emperor on PC II (Fig. 6) (Table 4). PC II reflected a difference between the standardised abundance and biomass and standardised age and length variables, indicating differential changes in population structures (Table 3). In 1995, 1996, and 1998, populations of common coral trout sampled off Mackay and Storm Cay differed from those off Townsville, with relatively little overlap in their PC II scores (Fig. 5). In 1996 and 1998, common coral trout sampled off Mackay and Townsville, respectively, also appeared to differ in their PC III scores from those off Storm Cay (Fig. 4). In contrast, populations of red throat emperor on reefs off Townsville and Mackay were more dissimilar, with limited overlap in their PC I scores in 1996 and 1997 (Fig. 5). Similarly, for red throat emperor, there was less overlap in the overall PC II scores from reefs off Townsville and Mackay than there was overlap between samples from Mackay and Storm Cay. This result was mainly influenced by the morphometric life-history parameters $\left(L_{90}, W_{90}, A_{90}\right)$ (Table 4 ; Fig. 6).

\section{Effects of year}

Significant and unconfounded main effects of year were evident for common coral trout on PC I and PC IV and for red throat emperor on PCs II-IV (Table 4), although the separation among years was less dramatic than that among zones or regions for both species. Mean PC IV scores for common coral trout were significantly greater in 1996, 1997, and 1998 than those in 1995 (Fig. 7) and were mainly influenced by sex ratio (Sex) and length of mature females $\left(L_{\mathrm{fem}}\right)$ (Table 3). In contrast, mean PC III scores for red throat emperor were significantly greater in 1997 and 1998 than those in 1995 and 1996, and PC IV scores were greater in 1995, 1996, and 1998 than those in 1997 (Fig. 7). Age and $A_{90}$ were the main life-history parameters influencing PC III, whereas Len was the main parameter underlying PC IV (Table 3).

Year $\times$ region interactions were also significant on PC II for common coral trout and PC I for red throat emperor (Fig. 5) and varied with both region and zone on PC III for common coral trout (Fig. 4). Plots of the interactions for PC II for common coral trout and PC I for red throat emperor indicated that populations on reefs in all three regions tended to cluster by year of sampling, albeit with some overlap in scores, particularly for Storm Cay (Fig. 5). Populations of common coral trout sampled off Townsville and Mackay demonstrated little overlap in their PC II scores in 1996 and 1998. Similarly, populations of common coral trout tended to cluster by zone, region, and year according to their PC III scores (Fig. 4). Red throat emperor sampled off Townsville in 1997 and 1998 and off Mackay in 1996 and 1997-1998 demonstrated little overlap in their PC I scores (Fig. 5).

\section{Classification power of PC scores}

Unbiased, jackknifed cross-validation tests on the significant PC (I-IV) scores for the combined data across years and regions indicated relatively high rates of classification success between open and closed reefs for both common coral trout and red throat emperor. Classification success (to zone) for common coral trout was $83 \%$ for open reefs and $89 \%$ for closed reefs, with a total error rate of $14 \%$. The analogous rates for red throat emperor were $75 \%$ (open reefs) and $86 \%$ (closed reefs) with a total error rate of $19 \%$. 
Table 4. Results of repeated-measures analysis of variance of within-group (repeated-measures) effects of year and between-group effects of region and zone for multivariate life-history indices (PCs) for common coral trout (Plectropomus leopardus) and red throat emperor (Lethrinus miniatus) collected from open and closed reefs off Townsville, Mackay, and Storm Cay, 1995-1998.

\begin{tabular}{|c|c|c|c|c|}
\hline \multirow[t]{2}{*}{ Term } & \multicolumn{4}{|l|}{$P>F$} \\
\hline & PC I & PC II & PC III & PC IV \\
\hline \multicolumn{5}{|l|}{ (a) Common coral trout } \\
\hline \multicolumn{5}{|l|}{ Within groups } \\
\hline Year & $\mathbf{0 . 0 0 2 3} *$ & 0.2295 & 0.0001 & 0.0077 \\
\hline Year $\times$ region & $0.2199 *$ & 0.0013 & 0.0044 & 0.5446 \\
\hline Year $\times$ zone & $0.5957 *$ & 0.5112 & 0.3111 & 0.5203 \\
\hline Year $\times$ region $\times$ zone & $0.4913 *$ & 0.0535 & 0.0001 & 0.1978 \\
\hline \multicolumn{5}{|l|}{ Between groups } \\
\hline Region & 0.1543 & 0.0003 & 0.0719 & 0.2719 \\
\hline Zone & $<0.0001$ & 0.8978 & 0.6113 & 0.9029 \\
\hline Region $\times$ zone & 0.6021 & 0.3482 & $0.0189 * *$ & 0.5366 \\
\hline \multicolumn{5}{|l|}{ (b) Red throat emperor } \\
\hline \multicolumn{5}{|l|}{ Within groups } \\
\hline Year & 0.0005 & 0.0002 & $<0.0001$ & 0.0022 \\
\hline Year $\times$ region & 0.0002 & 0.1828 & 0.4421 & 0.5285 \\
\hline Year $\times$ zone & 0.4320 & 0.0650 & 0.3234 & 0.3373 \\
\hline Year $\times$ region $\times$ zone & 0.2932 & $0.0384 * *$ & $0.0227 * *$ & 0.5092 \\
\hline \multicolumn{5}{|l|}{ Between groups } \\
\hline Region & 0.0787 & 0.0074 & $0.0198 * *$ & $0.0375 * *$ \\
\hline Zone & 0.0001 & $0.0443 * *$ & $0.0283 * *$ & 0.3546 \\
\hline Region $\times$ zone & 0.9183 & 0.1492 & 0.5029 & 0.5678 \\
\hline
\end{tabular}

Note: Tabulated values are probabilities of the observed data under the null hypotheses of no effect of the indicate terms. Bold values were statistically significant; *, probability adjusted for unequal correlations of within-group effects using Huynh-Feldt estimator; **, probability not significant at adjusted Bonferroni level for multiple testing $(P>$ $0.0125)$.

\section{Discussion}

We found clear evidence of accrued life-history benefits to fish populations in no-take zones compared with exploited populations outside such closed areas. Zone-related patterns in the multivariate life-history indices for both of the major target species of the reef line fishery on the GBR were consistent over large spatial and temporal scales. The nature of the overall differences in life-history indices between areas open and closed to fishing was consistent with a generally positive effect of no-take zones on the likely productivity and ecological sustainability of fish populations subject to exploitation in open areas. By analysing collectively a range of life-history parameters, we were able to clearly distinguish those populations that were sampled on reefs closed to fishing from those that were sampled from reefs historically open to fishing.

Populations of common coral trout and red throat emperor sampled within selected no-take zones of the GBRMP tended to have broader age and length distributions and greater abundance and biomass than populations in adjacent areas that had been subjected to fishing for many years. Lifehistory benefits of increased abundance, biomass, and size have been found for other exploited species within no-take zones elsewhere, or at least in areas that are not subjected to extractive activities such as fishing (Roberts and Polunin 1991; Russ and Alcala 1996a; Halpern and Warner 2002). We also found additional life-history benefits for common coral trout besides the typically measured parameters of abundance, biomass, and size, including increased survivorship, more males, and older and larger females, emphasizing further the apparent benefits of protecting populations of exploited fish in no-take zones. Such effects, including lower mortality rates and greater numbers of older and larger females, also have been found in other studies of common coral trout (Russ et al. 1998; Adams et al. 2000; Mapstone et al. 2004), though the effects were not consistently observed for all closed reefs examined (Mapstone et al. 1999, 2004).

Life-history characteristics accrued to populations of reef fish within no-take zones most likely lead to increased productivity (i.e., greater numbers of viable eggs and larvae). Populations with more diverse age and length distributions arising from enhanced survivorship, as we observed for common coral trout and red throat emperor on reefs closed to fishing, may have enhanced reproductive output and result in enhanced recruitment, both within and outside the no-take zones (Russ 2002). Marteinsdottir and Thorarinsson (1998) determined that age diversity within a spawning stock of cod (Gadus morhua) influenced recruitment, where increased diversity resulted in a more protracted spawning distribution, which maximised conditions for progeny survival. Similarly, Lambert (1990) found above average recruitment in herring (Clupea harengus) populations with more diverse age structures.

Adams et al. (2000) also found that female common coral trout above the size and age at recruitment to the fishery were significantly more abundant, larger, and older on reefs 
Fig. 2. Bi-plots of total data for multivariate life-history indices, principal components (PCs) I and II, for (a) common coral trout (Plectropomus leopardus) and (b) red throat emperor (Lethrinus miniatus) collected from open $(\square)$ and closed ( $\square$ ) reefs off Townsville, Mackay, and Storm Cay, 1995-1998. These plots demonstrate the significant between-group effect of zone on PC I for both species. Total variation in the data explained by PCs I and II was $64 \%$ and $72 \%$ for common coral trout and red throat emperor, respectively. The bi-plots represent both the original life-history parameters and transformed observations on the first two PCs, where the relative strength and influence of the original parameters are reflected by the size and direction of the arrows. See Table 2 for an explanation of abbreviations.

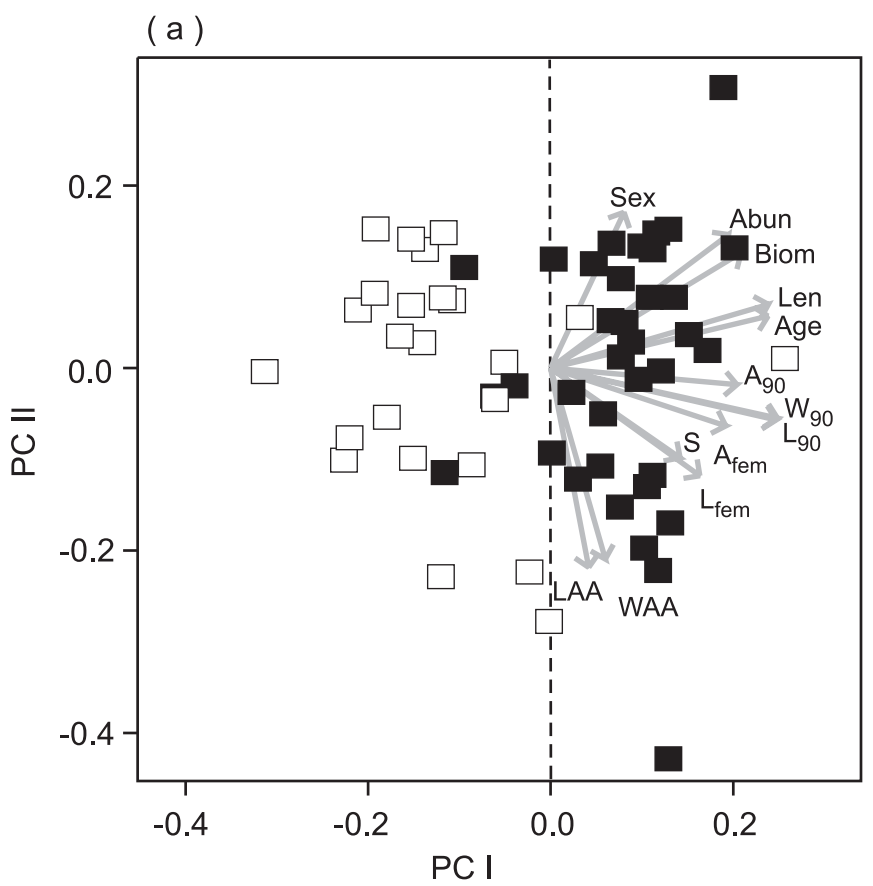

(b)

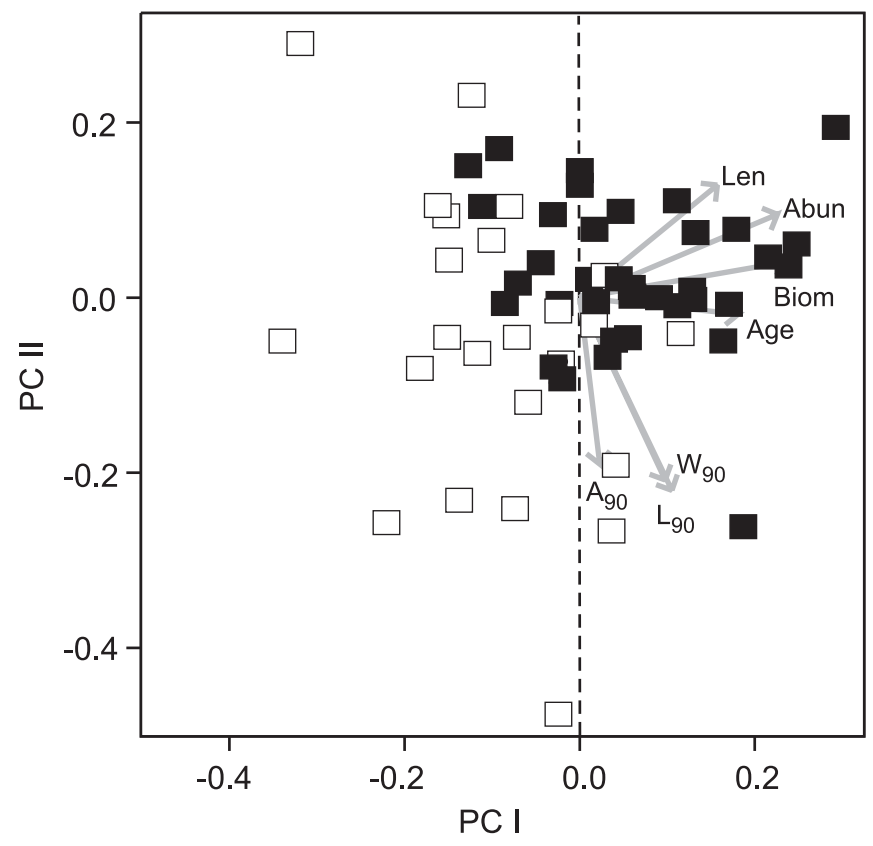

Fig. 3. Mean standardised plots of individual life-history parameters for total data of common coral trout (Plectropomus leopardus) and red throat emperor (Lethrinus miniatus) collected from open (open bars) and closed (solid bars) reefs off Townsville, Mackay, and Storm Cay, 1995-1998. See Table 2 for an explanation of abbreviations.

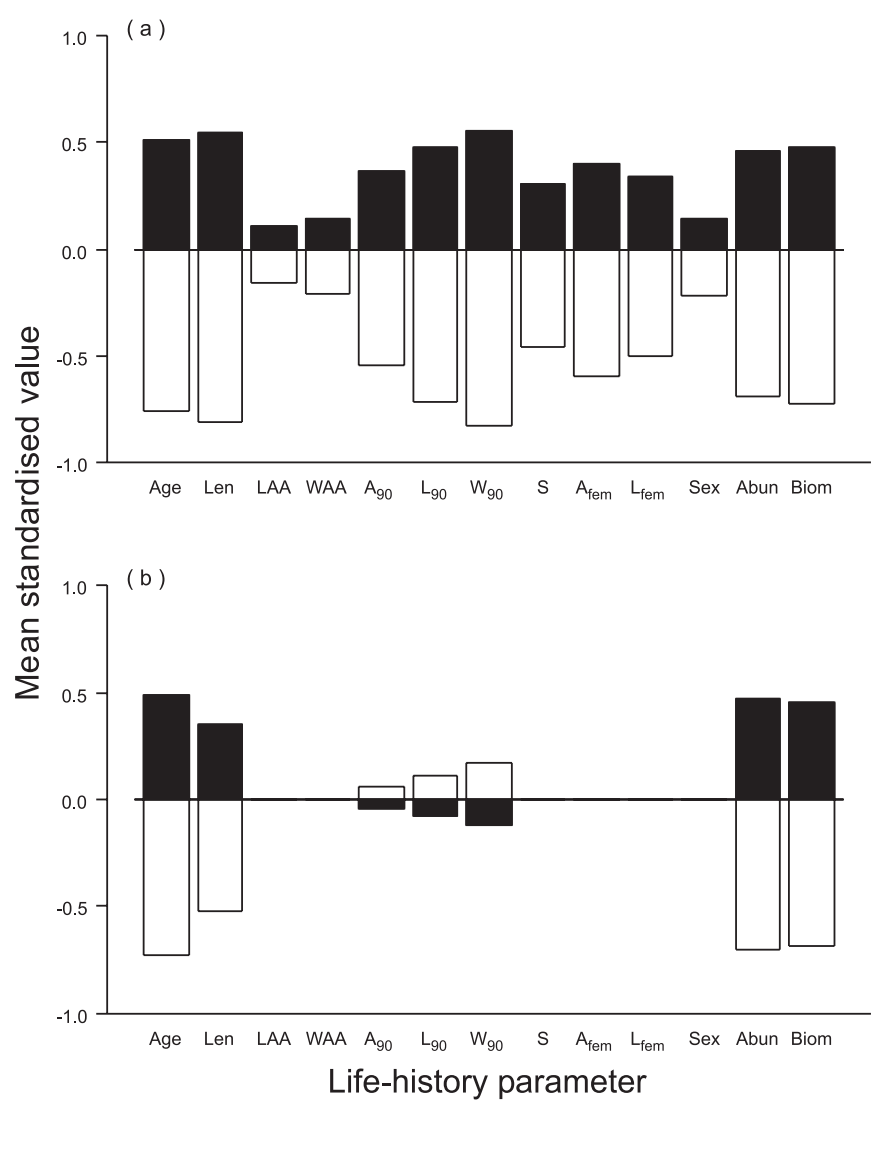

closed to fishing in the GBRWHA than those on reefs open to fishing and suggested that no-take zones were an effective insurance policy against fecundity limitation in protogynous hermaphrodites. Recent studies have also found that, as well as being more fecund, older, larger, and experienced ("repeat") spawning females also produce more viable progeny with traits that favour higher survivorship than those of younger, smaller, and first-time ("recruit") spawning females (e.g., Kjesbu et al. 1996; Marshall et al. 1998; Marteinsdottir and Steinarsson 1998). Older females also tend to have more protracted spawning seasons, thereby increasing the probability that their progeny will encounter favourable environmental conditions for growth and survival (Trippel 1998). In so far as these characteristics are likely to increase the prospects for survival and recruitment of offspring, selective removal or reduced abundance of larger and older individuals on grounds open to fishing may therefore have detrimental effects on the long-term sustainability of a population (Begg and Marteinsdottir 2002). There is a growing number of studies from temperate systems suggesting that the excessive removal of large, repeat spawners from a population, such as by fishing, may have greater impacts on recruitment success than simply removing absolute biomass (e.g., Marshall et al. 1998; Scott et al. 1999; Trippel 1999). In contrast, very lim- 
Fig. 4. Principal components (PCs) I and III for common coral trout (Plectropomus leopardus) collected from open (open symbols) and closed (solid symbols) reefs off Townsville (squares), Mackay (circles), and Storm Cay (triangles) in (a) 1995, (b) 1996, (c) 1997, and $(d)$ 1998. These plots demonstrate the significant interaction effect of zone, year, and region on PC III for common coral trout.

( a )

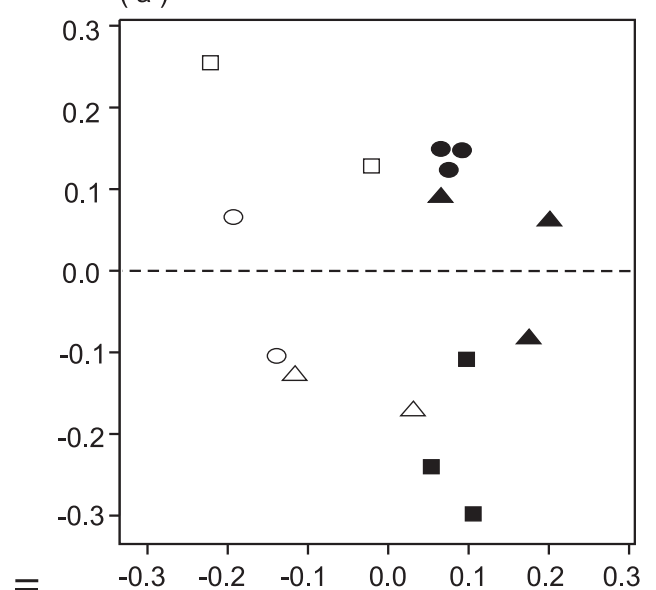

三

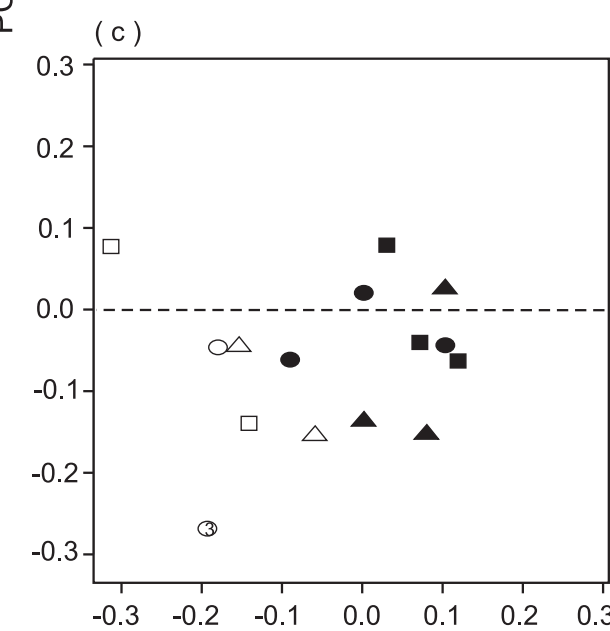

(b)

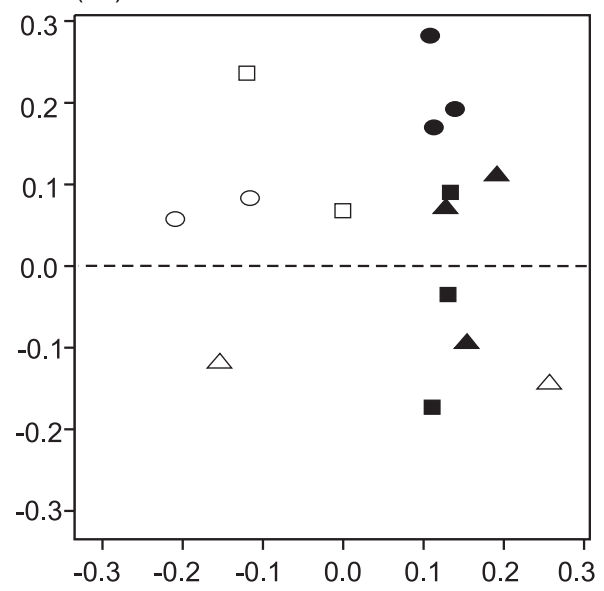

(d)

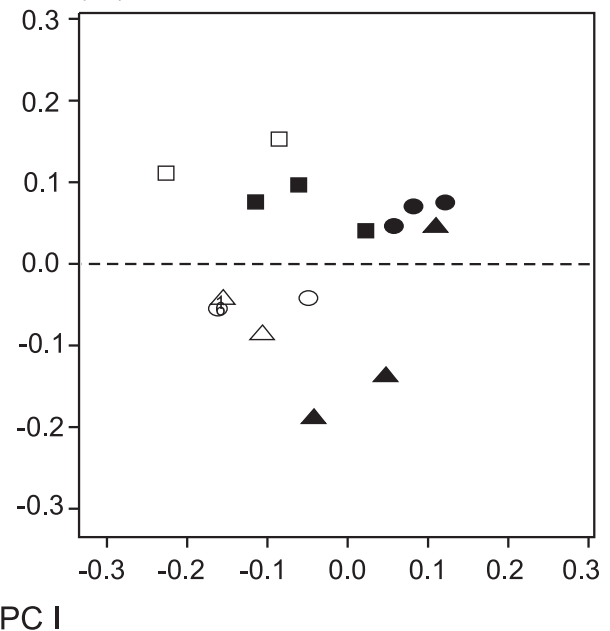

ited research on these impacts and associated maternal effects has been conducted on tropical reef fish species (Kerrigan 1997; McCormick 1998, 1999). The relevance of such effects in tropical systems needs to be investigated, particularly with respect to protogynous hermaphrodites (changing sex from female to male) such as common coral trout and red throat emperor, where the impacts of fishing may lead to reduction in abundances of mature, repeat spawning females through both direct removal by fishing and indirect removal via earlier sex change. Thus, populations with greater biomass and more abundant older and larger spawners, such as those in no-take zones, would be expected to lead to the production of greater numbers of more viable eggs and larvae and potentially result in fisheries benefits through spillover of adults or net export of larvae, or both, to surrounding areas where harvest occurs (e.g., Russ and Alcala 1996a; Roberts 1997; Russ 2002).

The benefits of net export of larvae from no-take zones might be expected to be greatest for populations of reef fish that are relatively sedentary, such as common coral trout (Davies 1995; Zeller and Russ 1998), because the zero or negligible flux of mature individuals across MPA boundaries means that there is no dilution of the effects of no-take zones through migration of mature fish to areas where they are vulnerable to fishing. In contrast, the benefits of spillover of adults from no-take zones would most likely be greatest in populations that are more mobile and reside outside the no-take zones for extended periods (Dahlgren and Sobel 2000). Red throat emperor may be such a species as tag-recapture data have indicated that these fish are capable of movements greater than $20 \mathrm{~km}$ across several reefs in a period of 6 months (Williams 2003; Bill Sawynok, Infofish Services, 142 Venables Street, North Rockhampton, Queensland 4701, Australia, unpublished data).

Although a clear separation was observed between populations of both common coral trout and red throat emperor sampled on reefs open and closed to fishing, the separation was more apparent (and subsequent classification total error rate lower) for populations of common coral trout than for populations of red throat emperor. The difference between the species might be due to the potentially more mobile lifehistory strategy of red throat emperor. Alternatively, the dif- 
Fig. 5. Principal components (PCs) I and II for common coral trout (Plectropomus leopardus) and red throat emperor (Lethrinus miniatus) collected from reefs off Townsville (open squares), Mackay (shaded squares), and Storm Cay (solid squares), 1995-1998. These plots demonstrate the significant interaction effect of region and year on PC II for common coral trout and PC I for red throat emperor.
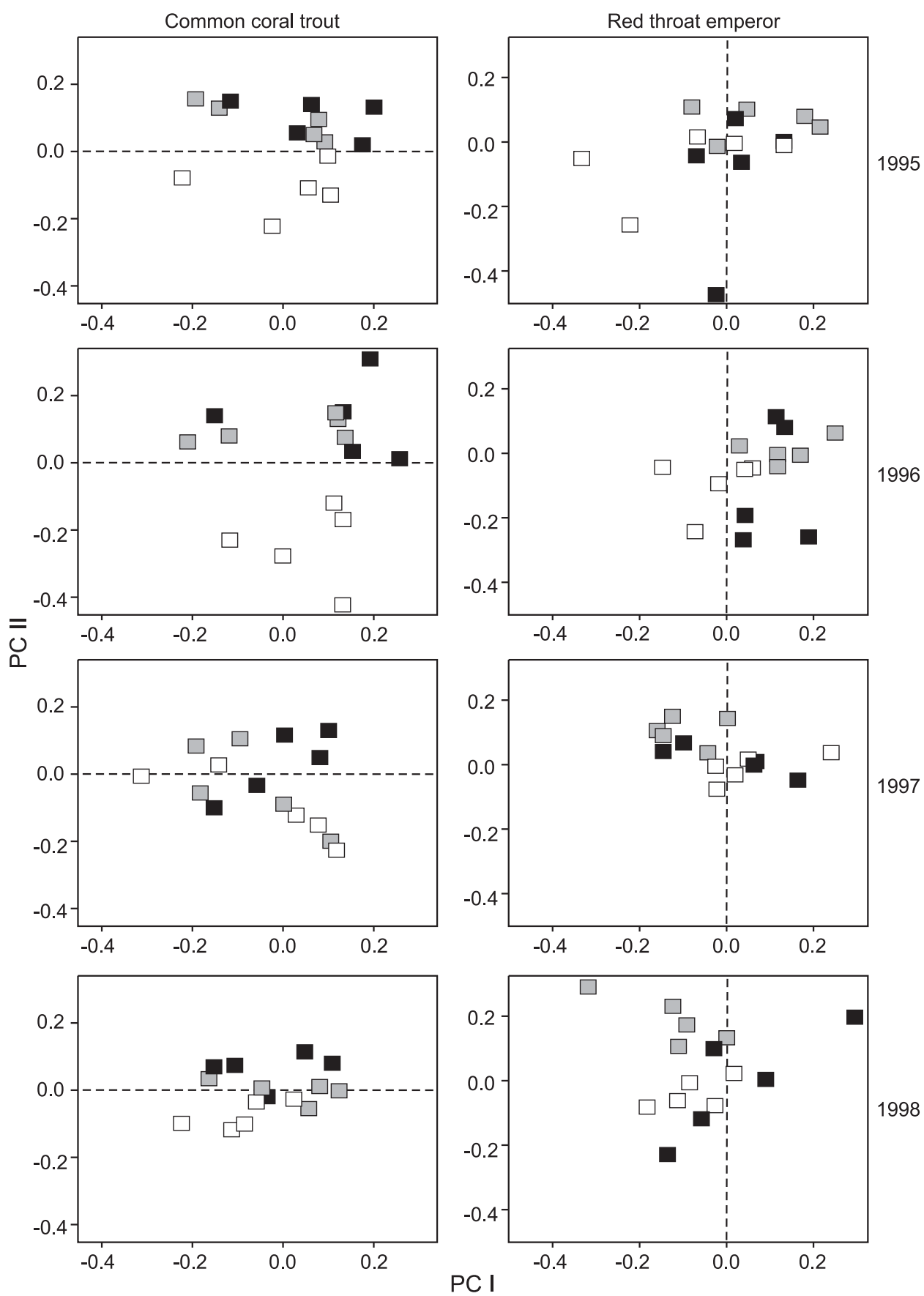

ferences might be an artefact of the greater number of common coral trout in our samples and the greater diversity of life-history parameters examined for this species. Similarly, the less consistent patterns observed for some of the morphometric life-history parameters $\left(A_{90}, L_{90}, W_{90}\right)$ for red throat emperor may reflect the species' greater movement combined with morphological patterns that perhaps reflect environmentally induced phenotypic variation derived from movements among different habitats (Stearns 1989; Swain and Foote 1999). Accordingly, the benefits and protection derived from no-take zones would potentially be reduced

more for red throat emperor than for the typically more siteattached common coral trout. The degree to which the benefits of no-take zones depend directly on rates of movement and home ranges of different species (Polacheck 1990; Bohnsack 2000; Cole et al. 2000) warrants more empirical examination, especially from a fishery perspective (Davies 1995; Crowder et al. 2000).

Most previous studies on the effects of no-take zones have included only a limited number of parameters, mainly abundance, biomass, and some measure of size (e.g., Buxton and Smale 1989; Roberts 1995; Russ and Alcala 1996b). We at- 
Fig. 6. Bi-plot of total data for multivariate life-history indices, principal components (PCs) I and II, for red throat emperor (Lethrinus miniatus) collected from reefs off Townsville (open squares), Mackay (shaded squares), and Storm Cay (solid squares), 1995-1998. This plot demonstrates the significant between-group effect of region on PC II for red throat emperor. Total variation in the data explained by PCs I and II was $72 \%$. The bi-plot represents both the original life-history parameters and transformed observations on the first two PCs, where the relative strength and influence of the original parameters are reflected by the size and direction of the arrows. See Table 2 for an explanation of abbreviations.

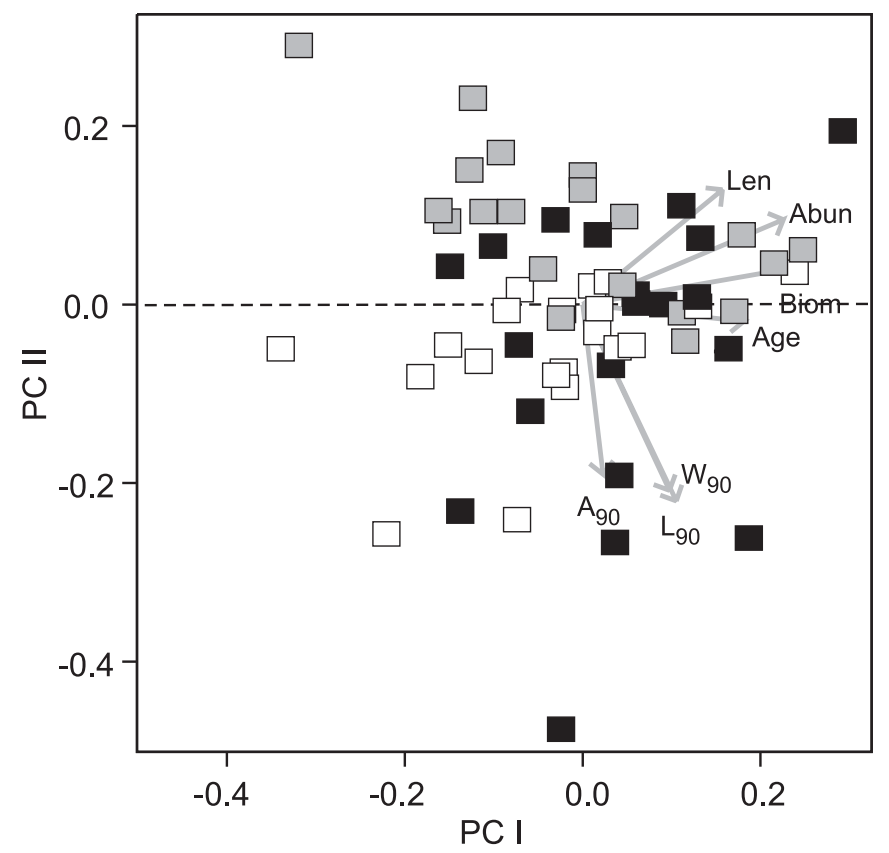

tempted to assimilate a diverse range of parameters that encapsulated more completely the life-history strategies of two species most likely to be impacted by fishing and, conversely, benefit from no-take zones on the GBR. Incorporating the information derived from these parameters into multivariate lifehistory indices provided a holistic view of differences between populations on open and closed reefs that were correlated with, and potentially brought about by, the implementation of no-take zones. Several of the parameters we used could be obtained only by killing the fish, emphasising that thorough assessments of performance of no-take zones will require some destructive sampling within these areas, as well as outside them. However, considering the relative harvests that have been removed from the respective reefs, we do not believe that the low level of destructive sampling used in this study impacted on the underlying population dynamics. In any given year and from any given reef, the maximum number of common coral trout and red throat emperor sampled were 396 fish and $454 \mathrm{~kg}$ and 112 fish and $166 \mathrm{~kg}$, respectively. In comparison, the average annual commercial harvests of demersal reef fish species (including common coral trout and red throat emperor, which constitute $55-75 \%$ of the harvest) in a $1^{\circ}$ latitude around each group of study reefs were about $600 \mathrm{t}$ in Storm Cay, $450 \mathrm{t}$ in Mackay, and $250 \mathrm{t}$ in Townsville (Mapstone et al. 2004). Furthermore, when the experimental closed reefs in each region were open to fishing in 1999, about $3 \mathrm{t}$ of common coral trout
Fig. 7. Bi-plots of total data for multivariate life-history indices principal components (PCs) I and IV for (a) common coral trout (Plectropomus leopardus) and PCs III and IV for (b) red throat emperor (Lethrinus miniatus) collected from reefs off Townsville, Mackay, and Storm Cay in 1995 (open squares), 1996 (lighter shaded squares), 1997 (darker shaded squares), and 1998 (solid squares). These plots demonstrate the significant within-group effect of year on PCs I and IV for common coral trout and PCs III and IV for red throat emperor. Total variation in the data explained by the PCs was $52 \%$ and $23 \%$ for common coral trout and red throat emperor, respectively. The bi-plots represent both the original life-history parameters and transformed observations on the respective PCs, where the relative strength and influence of the original parameters are reflected by the size and direction of the arrows. See Table 2 for an explanation of abbreviations.
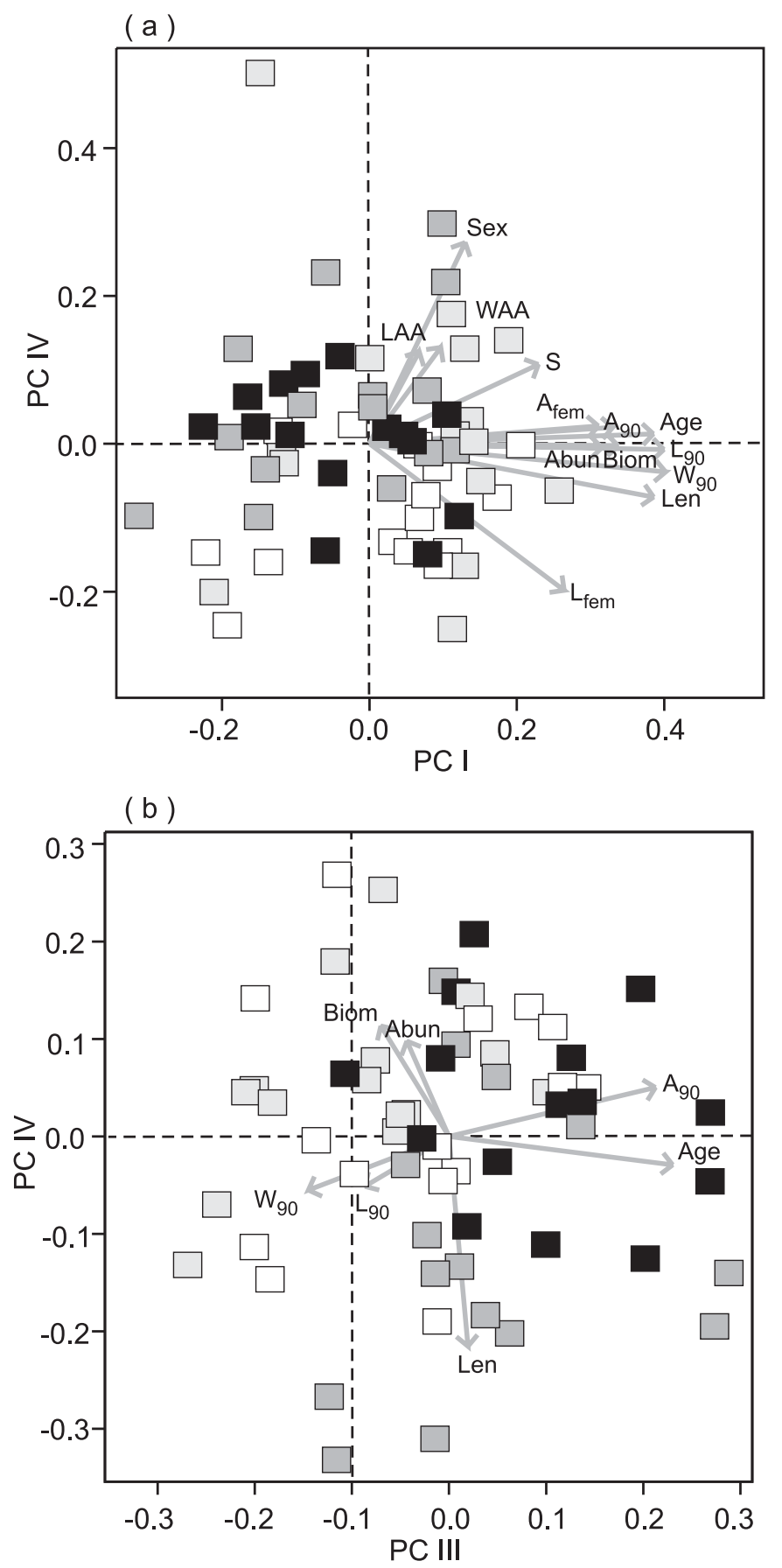
and $2 \mathrm{t}$ of other species (including red throat emperor) was harvested in a 2 -week period from these reefs. Consequently, it was assumed that the fish populations on each of our experimental reefs were not significantly impacted by our relatively low level of sampling, considering the harvests that have been observed on these and surrounding reefs.

Without such sampling and (or) monitoring designs as the CRC Reef ELF Experiment, it would not have been possible to obtain estimates of parameters used in this study to provide the holistic life-history perspective presented here. In addition, the temporal and spatial variability observed within and among populations of common coral trout and red throat emperor also demonstrated the need for routine and consistent monitoring programs over space and time to account for the inherent variability within life-history performance measures. Failure to account for such variation, for example, through sampling at only one time or in one area, has the potential to generate significantly misleading results about the merits or otherwise of MPA strategies such as no-take zones (Mapstone et al. 2004). Ultimately, though, the degree of assessment should depend on the objectives for establishing the MPA in the first place. Management agencies should recognise the importance of structured, regular research sampling and (or) monitoring programs if there is a genuine interest in determining the performance of MPAs, rather than accepting on faith that they achieve desired outcomes. Generally, however, once MPAs are established, there is very little monitoring to determine their performance and efficacy (Russ and Alcala 1996b; Agardy 1997), even though this should be the default scenario within an effective management framework.

No-take zones have been advocated as a management strategy that embodies the precautionary approach by providing an insurance against the uncertainty that pervades traditional fisheries management (Agardy 1997; Bohnsack 2000). Although no-take zones most likely provide an array of conservation benefits within their boundaries, we should be cautious in extrapolating these results to direct fisheries benefits. The extent to which fisheries benefits will be realised is as dependent on what happens outside the no-take zone (i.e., the nature of the fisheries management regime in the area open to fishing) as what happens inside (Beverton and Holt 1957; Polacheck 1990; Mapstone et al. 2004). Notably, when designing MPAs and particularly no-take zones, we need to incorporate a routine monitoring and assessment program to evaluate the performance of the areas to determine if they are indeed achieving the objectives for which they were established (Mapstone et al. 1999; Agardy 2000; Russ 2002). If an MPA is not fulfilling such objectives, then management needs to be able to adapt accordingly. If these objectives are related to sustaining fisheries production outside the no-take zones or MPAs, then examining a multivariate suite of life-history parameters as part of a routine monitoring program should provide a holistic performance indicator to measure the performance of MPAs in relation to exploited fish species.

\section{Acknowledgements}

We would like to thank the CRC Reef Fishing and Fisheries team for collecting and processing the data, Robin Stewart and Mary Petersen for tireless operational support in the field, and Jon Day for comments on the draft manuscript.
Funding for this research was provided by the Cooperative Research Centre for the Great Barrier Reef Word Heritage Area, the Fisheries Research and Development Corporation, and the Great Barrier Reef Marine Park Authority. This manuscript is a contribution from the CRC Reef Effects of Line Fishing Project.

\section{References}

Adams, S. 2002. The reproductive biology of three species of Plectropomus (Serranidae) and responses to fishing. PhD. thesis, James Cook University, Townsville, Australia.

Adams, S. 2003. Morphological ontogeny of the gonad of three plectropomid species through sex differentiation and transition. J. Fish Biol. 63: 22-36.

Adams, S., Mapstone, B.D., Russ, G.R., and Davies, C.R. 2000. Geographic variation in the sex ratio, sex-specific size, and age structure of Plectropomus leopardus (Serranidae) between reefs open and closed to fishing on the Great Barrier Reef. Can. J. Fish. Aquat. Sci. 57: 1448-1458.

Agardy, T.S. 1997. Marine protected areas and ocean conservation. Academic Press, San Diego, Calif.

Agardy, T.S. 2000. Information needs for marine protected areas: scientific and societal. Bull. Mar. Sci. 66: 875-888.

Allison, G.W., Lubchenco, J., and Carr, M.H. 1998. Marine reserves are necessary but not sufficient for marine conservation. Ecol. Appl. 8(Suppl.): S79-S92.

Bean, K., Mapstone, B.D., Davies, C.R., Murchie, C.D., and Williams, A.J. 2003. Gonad development and evidence of protogyny in the red throat emperor (Lethrinus miniatus: Bloch and Schneider) on the Great Barrier Reef. J. Fish Biol. 62: 299-310.

Begg, G.A., and Marteinsdottir, G. 2002. Environmental and stock effects on spatial distribution and abundance of mature cod Gadus morhua. Mar. Ecol. Prog. Ser. 229: 245-262.

Beverton, R.J.H., and Holt, S.J. 1957. On the dynamics of exploited fish populations. Fisheries Investigations Series II, Vol. XIX, Ministry of Agriculture, Fisheries and Food, Lowestoft.

Bohnsack, J.A. 1998. Application of marine reserves to reef fisheries management. Aust. J. Ecol. 23: 298-304.

Bohnsack, J.A. 2000. A comparison of the short-term impacts of no-take marine reserves and minimum size limits. Bull. Mar. Sci. 66: 635-650.

Buxton, C.D. 1993. Life-history changes in exploited reef fishes on the east coast of South Africa. Environ. Biol. Fishes, 36: 47-67.

Buxton, C.D., and Smale, M.J. 1989. Abundance and distribution patterns of three temperate marine reef fish (Teleostei: Sparidae) in exploited and unexploited areas off the southern cape coast. J. Appl. Ecol. 26: 441-451.

Cole, R.G., Villouta, E., and Davidson, R.J. 2000. Direct evidence of limited dispersal of the reef fish Parapercis colias (Pinguipedidae) within a marine reserve and adjacent fished areas. Aquat. Conserv. Mar. Freshw. Ecosyst. 10: 421-436.

Crowder, L.B., Lyman, S.J., Figueira, W.F., and Priddy, J. 2000. Source-sink population dynamics and the problem of siting marine reserves. Bull. Mar. Sci. 66: 799-820.

Dahlgren, C.P., and Sobel, J. 2000. Designing Dry Tortugas Ecological Reserve: how big is big enough? ... to do what? Bull. Mar. Sci. 66: 707-719.

Davies, C.R. 1995. Patterns of movement of three species of coral reef fish on the Great Barrier Reef. PhD. thesis, James Cook University, Townsville, Australia. 
Davies, C.R., Mapstone, B.D., Ayling, A., Lou, D.C., Punt, A.E., Russ, G.R., Samoilys, M.A., Smith, A.D.M., Welch, D.J., and Williams, D.M. 1998. Effects of line fishing experiment 19951997: project structure and operations. A supplementary document to progress report. CRC Reef Research Centre, Townsville, Australia.

Day, J.C. 2002. Zoning — lessons from the Great Barrier Reef Marine Park. Ocean Coast. Manag. 45: 139-156.

Dugan, J.E., and Davis, G.E. 1993. Applications of marine refugia to coastal fisheries management. Can. J. Fish. Aquat. Sci. 50: 2029-2042.

Ferreira, B.P. 1995. Reproduction of the common coral trout Plectropomus leopardus (Serranidae: Epinephelinae) from the central and northern Great Barrier Reef, Australia. Bull. Mar. Sci. 56: 653-669.

Ferreira, B.P., and Russ, G.R. 1994. Age validation and estimation of growth rate of the coral trout, Plectropomus leopardus (Lacépède 1802), from Lizard Island, northern Great Barrier Reef. Fish. Bull. 92: 46-57.

Fogarty, M.J., Bohnsack, J.A., and Dayton, P.K. 2000. Marine reserves and resource management. In Seas at the millennium: an environmental evaluation. Edited by C.R.C. Sheppard. Pergamon, Oxford. pp. 375-392.

GBRMPA. 2004. New GBR zoning. Available at the Great Barrier Reef Marine Park Authority website: www.gbrmpa.gov.au/ corp_site/management/zoning/index.html.

Halpern, B.S. 2003. The impact of marine reserves: do reserves work and does reserve size matter? Ecol. Appl. 13(Suppl. 1): S117-S137.

Halpern, B.S., and Warner, R.R. 2002. Marine reserves have rapid and lasting effects. Ecol. Lett. 5: 361-366.

Higgs, J.B. 1996. A review of published fisheries dependent and independent surveys of the recreational Great Barrier Reef line fisheries and demersal reef fish stocks. Report to the Queensland Fisheries Management Authority, CRC Reef Research Centre, Townsville.

Kerrigan, B.A. 1997. Variability in larval development of a tropical reef fish (Pomacentridae: Pomacentrus amboinensis): the parental legacy. Mar. Biol. 127: 395-402.

Kjesbu, O.S., Solemdal, P., Bratland, P., and Fonn, M. 1996. Variation in annual egg production in individual captive Atlantic cod (Gadus morhua). Can. J. Fish. Aquat. Sci. 53: 610-620.

Lambert, T.C. 1990. The effect of population structure on recruitment in herring. J. Cons. Int. Explor. Mer, 47: 249-255.

Mapstone, B.D., McKinlay, J.P., and Davies, C.R. 1996. A description of the commercial reef line fishery logbook data held by the Queensland Fisheries Management Authority. Report to the Queensland Fisheries Management Authority, CRC Reef Research Centre, Townsville.

Mapstone, B.D., Ayling, A.M., and Choat, J.H. 1999. A visual survey of demersal biota in the Cairns section of the Great Barrier Reef Marine Park. Great Barrier Reef Marine Park Authority Res. Publ. Ser. 60: 1-47.

Mapstone, B.D., Davies, C.R., Little, L.R., Punt, A.E., Smith, A.D.M., Pantus, F., Lou, D.C., Williams, A.J., Jones, A., Ayling, A.M., Russ, G.R., and MacDonald, A.D. 2004. The effects of line fishing on the Great Barrier Reef and evaluations of alternative potential management strategies. CRC Reef Research Centre Technical No. 52, CRC Reef Research Centre, Townsville, Australia.

Marshall, C.T., Kjesbu, O.S., Yaragina, N.A., Solemdal, P., and Ulltang, O. 1998. Is spawner biomass a sensitive measure of the reproductive and recruitment potential of Northeast Arctic cod? Can. J. Fish. Aquat. Sci. 55: 1766-1783.
Marteinsdottir, G., and Steinarsson, A. 1998. Maternal influence on the size and viability of Iceland cod Gadus morhua eggs and larvae. J. Fish Biol. 52: 1241-1258.

Marteinsdottir, G., and Thorarinsson, K. 1998. Improving the stock-recruitment relationship in Icelandic cod (Gadus morhua) by including age diversity of spawners. Can. J. Fish. Aquat. Sci. 55: $1372-1377$.

McCormick, M.I. 1998. Behaviourally induced maternal stress in a fish influences progeny quality by a hormonal mechanism. Ecology, 79: 1873-1883.

McCormick, M.I. 1999. Experimental test of the effect of maternal hormones on larval quality of a coral reef fish. Oecologia, 118: 412-422.

Mosquera, I., Côté, I.M., Jennings, S., and Reynolds, J.D. 2000. Conservation benefits of marine reserves for fish populations. Anim. Conserv. 4: 321-332.

Murray, S.N., Ambrose, R.F., Bohnsack, J.A., Botsford, L.W., Carr, M.H., Davis, G.E., Dayton, P.K., Gotshall, D., Gunderson, D.R., Hixon, M.A., Lubchenco, J., Mangel, M., MacCall, A., McArdle, D.A., Ogden, J.C., Roughgarden, J., Starr, R.M., Tegner, M.J., and Yoklavich, M.M. 1999. No-take reserve networks: sustaining fishery populations and marine ecosystems. Fisheries, 24: 11-25.

Polacheck, T. 1990. Year around closed areas as a management tool. Nat. Res. Model. 4: 327-354.

Quinn, T.J., II, and Deriso, R.B. 1999. Quantitative fish dynamics. Oxford University Press, New York.

Roberts, C.M. 1995. Rapid build-up of fish biomass in a Caribbean marine reserve. Conserv. Biol. 9: 815-826.

Roberts, C.M. 1997. Connectivity and management of Caribbean coral reefs. Science (Wash., D.C.), 278: 1454-1457.

Roberts, C.M., and Polunin, N.V.C. 1991. Are marine reserves effective in management of reef fisheries? Rev. Fish Biol. Fish. 1: 65-91.

Roberts, C.M., Bohnsack, J.A., Gell, F., Hawkins, J.P., and Goodridge, R. 2001. Effects of marine reserves on adjacent fisheries. Science (Wash., D.C.), 294: 1920-1923.

Russ, G.R. 2002. Marine reserves as reef fisheries management tools: yet another review. In Coral reef fishes. Edited by P. Sale. Academic Press, Sydney, Australia. pp. 421-444.

Russ, G.R., and Alcala, A.C. 1996a. Do marine reserves export adult fish biomass? Evidence from Apo Island, central Philippines. Mar. Ecol. Prog. Ser. 132: 1-9.

Russ, G.R., and Alcala, A.C. 1996b. Marine reserves: rates and patterns of recovery and decline of large predatory fish. Ecol. Appl. 6: 947-961.

Russ, G.R., Lou, D.C., Higgs, J.B., and Ferreira, B.P. 1998. Mortality rate of a cohort of the coral trout, Plectropomus leopardus, in zones of the Great Barrier Reef Marine Park closed to fishing. Mar. Freshw. Res. 49: 507-511.

SAS. 1989. SAS/STAT user's guide. Version 6. 4th ed. Vol. 2. SAS Institute Inc., Cary, N.C.

Scott, B., Marteinsdottir, G., and Wright, P. 1999. Potential effects of maternal factors on spawning stock-recruitment relationships under varying fishing pressure. Can. J. Fish. Aquat. Sci. 56: $1882-1890$

Sokal, R.R., and Rohlf, F.J. 1995. Biometry. The principles and practice of statistics in biological research. W.H. Freeman and Company, New York.

Stearns, S.C. 1989. The evolutionary significance of phenotypic plasticity. Bioscience, 39: 436-445.

Swain, D.P., and Foote, C.J. 1999. Stocks and chameleons: the use of phenotypic variation in stock identification. Fish. Res. 43: 113-128. 
Trippel, E.A. 1998. Egg size and viability and seasonal offspring production of young Atlantic cod. Trans. Am. Fish. Soc. 127: 339-359.

Trippel, E.A. 1999. Estimation of stock reproductive potential: history and challenges for Canadian Atlantic gadoid stock assessments. J. Northw. Atl. Fish. Sci. 25: 61-81.

Vincent, A.C.J., and Sadovy, Y.J. 1998. Reproductive ecology in the conservation and management of fishes. In Behavioural ecology and conservation biology. Edited by T.M. Caro. Oxford University Press, New York. pp. 209-245.
Williams, A.J. 2003. Spatial patterns in population biology of a large coral reef fish: what role can movement play? Ph.D. thesis, James Cook University, Townsville, Australia.

Williams, A.J., Davies, C.R., Mapstone, B.D., and Russ, G.R. 2003. Scales of spatial variation in demography of a large coralreef fish - an exception to the typical model? Fish. Bull. 101: 673-683.

Zeller, D.C., and Russ, G.R. 1998. Marine reserves: patterns of adult movement of the coral trout (Plectropomus leopardus (Serranidae)). Can. J. Fish. Aquat. Sci. 55: 917-924. 